\section{Research of possibilities of studying the areas of development of erosion of slope lands in Azerbaijan and fight it}

\author{
Rans Aliev ZH* \\ Institute of Erosion and Irrigation of NAS of Azerbaijan, Azerbaijan
}

\section{Annotation}

The study proved that in gully systems with the largest catchment area ranging from 5.0 to $28.8 \mathrm{~km} 2$, the degree of dismemberment of gully systems is small, varies mainly from 1 to $3 \mathrm{~km}$ $/ \mathrm{km} 2$, less often from 3 to $5 \mathrm{~km} / \mathrm{km} 2$. As can be seen, the average annual growth of ravines is $0.34 \ldots 7.48 \mathrm{~m}$ in length, $0.20 \ldots 2.48 \mathrm{~m}$ in width, $0.10 \ldots 1.16 \mathrm{~m}$ in depth. The intensity of erosion development (ravine, planar, etc.) is mediated by their catchment area. Moreover, the degree of division of individual gully systems here is not dependent on their catchment area, moreover, the greatest dissection is observed in gully systems that have the smallest catchment area, which is associated with the conditions of their location.

\section{More Information}

Submitted: 10 October 2018

Approved: 12 July 2019

Published: 15 July 2019

How to cite this article: Rans Aliev ZH. Research of possibilities of studying the areas of development of erosion of slope lands in Azerbaijan and fight it. Ann Civil Environ Eng. 2019; 3: 040-044.

DOI: dx.doi.org/10.29328/journal.acee.1001016

Copyright: @ 2019 Rans Aliev ZH. This is an open access article distributed under the Creative Commons Attribution License, which permits unrestricted use, distribution, and reproduction in any medium, provided the original work is properly cited

Keywords: Gully erosion; Arid zones; Erosion; Republic of azerbaijan found that gully erosion covers

ISSN: 2574-0350

Check for updates

\section{Introduction}

Azerbaijan it occupies a rather large area in the zone of insufficient moisture and is used in agriculture as winter pastures. As is well known, fallow soils are by nature very susceptible to erosion. Examples of the fact that, in conditions of acute shortage of natural moisture due to unsystematic use of arable land (which is already very little) led to the widespread development of erosion, different reduction of their productivity, «exposure» of entire massifs and mountain slopes.

Since the natural conditions and the nature of the formation of erosion in the arid zone of Azerbaijan have their own specific features, the existing methods of dealing with plane and gully erosion will not be acceptable for the conditions of this zone.

Consequently, the issue of developing a set of measures to combat soil erosion and, first of all, the study of the distribution area and the intensity of the development of planar erosion and gully erosion, identifying the factors causing accelerated erosion becomes urgent.

It should be recognized that the problem of soil protection from erosion is very relevant for the Azerbaijan Republic [1 $-5]$.

\section{Object and Methods of Research}

The investigations were carried out on the soils of the territory of the Tertiary Plateau on an area of 72,000 hectares in the period 2007-2016. The study area occupies the foothill part of the southern slope of the Greater Caucasus (between the Alazano-Agrichay valley in the north and the Kura-Araks lowland in the south) and extends parallel to the general direction of the Main Caucasus Range from northwest to southeast. The northern part of the region is a continuation of the Dashyuzsky ridge with the highest marks of $624 \ldots 764$ $\mathrm{m}$, in the southern part there is the Ahar-Bahar range with individual peaks 468 ... $595 \mathrm{~m}$ above sea level.

Geomorphologically, this area belongs to the foothills and low mountains. The terrain is wide-leaved, represented by a ravine net, plains and hilly-plateau-like rises. According to the geological structure, the study area is a relatively young formation, which is composed of sediments of the Tertiary and Quaternary time. The main soil-forming rocks here are pebble beds, sandstones, carbonate and gypsum-bearing clays, as well as loess-like loams, compliant with washout and erosion.

The climate is moderately warm with a dry winter and hot dry summer. The average annual air temperature is $12 \ldots 14$ ${ }^{\circ} \mathrm{C}$. The average temperature of the hottest month (July) is 25 $26^{\circ} \mathrm{C}$, the coldest (January) $-0 \ldots 2^{\circ} \mathrm{C}$.

*Address for Correspondence: Rans Aliev ZH. Institute of Erosion and Irrigation of NAS of Azerbaijan, Azerbaijan, Tel: +994504242130;

Email: zakirakademik@mail.ru 
Atmospheric precipitation falls $250 \ldots 400 \mathrm{~mm}$ per year. The greatest number of them is observed in the spring $(95 \ldots$ $125 \mathrm{~mm})$, the smallest - in the summer $(40 \ldots 70 \mathrm{~mm})$. In most cases, they fall out in the form of showers, which contribute to the intensive development of erosion processes.

The spring maximum of precipitation coincides with the period of intensive vegetation, which favors good development in the wildfire of crops, mainly cereals. The snow cover is unstable, which contributes to the development of erosion in winter.

Vegetation cover is characterized mainly by steppe formations. Its main representatives are a feather-grass, a bearded man, a fescue, a wheat grass, a pig, and various ephemeral cereals with single shrubs of the tree.

The study of soil, their erodism and the intensity of development of erosion processes was carried out by comparativegeographical, experimental and stationary methods [6-9].

Studied the patterns of development of ravines, taking into account the category of economic use of soil, the average annual growth of ravines, where the measurement of the projective cover by the method of the framework was carried out, was determined by the established rappers. At $68.3 \%$ of the area, the dispersion is $2.0 \ldots 7.0 \mathrm{~km} / \mathrm{km} 2$, and the density of ravines in some places reaches 15.5 cubic meters. $\mathrm{km} 2$.

The length of the ravines is $0.34 \ldots 7.48 \mathrm{~m}$, the maximum width is $0.20 \ldots 2.48 \mathrm{~m}$, the depth is $0.10 \ldots 1.16 \mathrm{~m}$. The catchment area affects the intensity of the development of the ravines. Out of 79 ravine systems with a small catchment area from 0.02 to $0.47 \mathrm{~km} 2$, only 4 have a cutting degree of less than $1.0 \mathrm{~km} / \mathrm{km} 2$, and in 36 ravine systems - $5.0 \ldots 7.5 \mathrm{~km} /$ $\mathrm{km} 2$, 12-year-old - from 7.5 to $10.0 \mathrm{~km} / \mathrm{km} 2$, 4 ravines - from 10.0 to 15.0 , and one ravine system has more than $15 \mathrm{~km} /$ $\mathrm{km} 2$. The degree of division of individual systems of ravines depends on their catchment area that is connected with the conditions of their stay.

Observations on the growth of ravines in length were carried out on several ravines of each "key". At the beginning and at the end of the year, the tops of the ravines were surveyed, by binding them to reference points or to fixed points on the ground. In the course of the study, we identified areas prone to gullying, established by office processing on the basis of topographic maps, the results of which were used to develop an electronic map to determine the potential erosion hazard of soils in the region, a study on a scale of 1 : 50,000 . The main morphometric and morphological elements of the ravines were determined in the office conditions on a large-scale cartographic basis, as well as on the materials of measurements directly in the field in the system of a separate gully system. The growth rate of the ravines was installed in a vertical position with a geodetic rail or other calibrated instruments (tacheometers, GPS), carried out within the framework of a joint project of the Azerbaijan-Poland Commonwealth. The eroding flow rate was studied in soils by the method of MS Kuznetsova [10]. Research results and discussion: Conducted large-scale soil-erosion studies show that ravine erosion among regions of Azerbaijan that sharply differ in their natural conditions is most widely used on the tertiary plateau.

The territory of the tertiary plateau is located entirely in the arid zone, where semi-desert type of soil formation is, 11 , 12,13 , over an area of 72 thousand hectares. Earlier studies have also revealed the mapping of mountain gray-brown light and gray-brown soils of varying degrees of alkalinity, salinity and thickness of the fine-grained layer, grain size distribution and degree of erodedness.

Mountain gray-brown light soils occupy a vast area 37086.5 hectares or $50.95 \%$ of the total area. Of these, 4,556 hectares are not prone to erosion, 7,487.5 hectares are weakly washed away, 7,909.5 hectares are moderate, and 1, 7152.5 hectares are strongly. On these soils, depending on the degree of washing and the particle-size composition, the humus content varies from 0.41 to $2.62 \%$.

Soils are characterized by a weak ion absorption capacity. In eroded soils, the sum of absorbed $\mathrm{Ca}, \mathrm{Mg}$ and $\mathrm{Na}$ ions varies within the limits of $7.78 \ldots 20.0 \mathrm{mg} / \mathrm{eq}$, which is related to the composition of the soil-forming rocks. Characterized soils in most cases are subject to erosive action of water. Only in the upper layers of non-washed soils, washed out on an inclined plain, the content of water-resistant aggregates $>1.0 \mathrm{~mm}$ reaches $43.8 \%$, and in washed-off soils it varies within the limits of $1.6 \ldots 34.2 \%$.

The eroding bottom flow velocity is $0.45 \ldots 0.055 \mathrm{~m} / \mathrm{s}$. Sulfur-rich soils cover an area of $24,242.5$ hectares or $33.32 \%$ of the territory and cover the eastern part of Palantokan Mountain and the entire southern slope of Khojashin Mountain. Of these, 2,520.0 hectares are eroded to a low degree, 1,747.5 hectares are medium and 9,090.0 hectares are strong. The humus content is low (1.78\%) in the upper horizon; gross nitrogen is $0.15 \%$. These values decrease in eroded varieties, in strongly washed quantities they reach $0.67 \%$ of humus and $0.006 \%$ of nitrogen.

The amount of absorbed $\mathrm{Ca}, \mathrm{Mg}$ and $\mathrm{Na}$ ions is $15.56 \ldots$ $20.67 \mathrm{mg} / \mathrm{eq}$, of which the proportion of absorbed sodium is $4.57 \ldots 15.01 \%$ of the absorption capacity, which indicates a noticeable salinity of sulfur -- brown soil object of study. Gray-brown soils are very malleable to the erosion effect of water. It has been established that even in unwashed varieties, the sum of water-resistant aggregates with a size of $>1.0 \mathrm{~mm}$ (Savinov) along the profile varies within $1.4 \ldots 27.4 \%$ of the blurring bottom flow velocity, which is $0.039 \ldots 0.041 \mathrm{~m} / \mathrm{s}$.

As a result of ravine erosion, a significant area of sloping lands of the studied territory has already lost its economic 
value, there is a sedimentation of the Mingechaur reservoir with erosion products transferred through deep gorges from the slopes of the adjacent mountains "13". Some authors believe that a high growth rate of ravines remains in arid conditions and continues to progress $[1,3,5,11,12,13]$.

Observations show that, on the territory of the tertiary plateau, the intensive growth of ravines is connected, first of all, with the looseness of the ground and a sharp drop in the slope of the plain towards the Kura-Araz lowland and the Mingechaur reservoir. The beginning ravine quickly deepens to the level of a water mirror, grows in length and width by collapsing its walls.

The growth of ravines accelerates in the places of formation of cracks and subsidence, which is abundant They are especially on the right bank sloping plain. If cracks and subsidence are formed far from the existing ravines and the steep bank of the reservoir, then their growth subsequently fades away, and where the cracks and subsidence reach the ravine, they develop and change into the shape of ravines and accelerate the dismemberment of the territory. The reason for the formation of cracks and subsidence in the area has not been studied exactly.

Probably the lower layers of loose soil occurs, on the one hand, compaction, and on the other - the formation of voids, where after the precipitation of heavy and prolonged rains occur the described phenomena. The length of such cracks and subsidence sometimes reaches $100 \ldots 180 \mathrm{~m}$. The width of the cracks in the initial stage is about $3 \ldots 5 \mathrm{~cm}$, and sometimes even less. According to some researchers, as the cracks expand, so does the shedding and collapse of their walls [8] happens. The size of the subsidence is also different: the largest diameter of the funnels reaches $3.7 \mathrm{~m}$, and the depth - up to $8.0 \mathrm{~m}$.

It should be noted that the intensity of the development of ravines in the arid zone is affected not only by the friability of the soil and the sharp drop in the basis of erosion, but also by light particle size the composition of soils and breeds (mainly sandy and light loamy), their erosion compliance, a large steepness of the slopes with frequently repeated cliffs, rare vegetation cover and short growing season of the most common herbaceous plants here. The main reason for the widespread ravine erosion, in the opinion of the authors of this study, was the lowering of the erosion base in the past: deep penetration of the Kura river bed in the area between the Khojashin and Bozdag ridges, which allowed water flows from the adjacent mountains to reach the Kura River.

Formed in this way numerous ravines are in various stages of their development.

The studies and calculations performed on the map of the degree of dissection of the territory by the ravine net made by the authors of this work showed that the territory of the Mingechaur reservoir is subject to gully erosion to varying degrees.
The data of these calculations are given in, from the data of which it is seen that only $8.3 \%$ of the area of the territory is poorly divided (less than $0.5 \mathrm{~km} / \mathrm{km} 2$ ). In the main part of the territory (83.1\%), this (Figure 1) varies from 0.5 to 5.0 $\mathrm{km} / \mathrm{km} 2$. Tertiary plateau territory distribution according to the degree of dissection the degree of "destruction" of the territory by ravines the degree of dissection, $\mathrm{km} / \mathrm{km} 2$ Area of each gradation of division

The area of groups of division of ha\%\% ha Weak $0.30 .3 \ldots$ $0.53950 .02057,55.42 .96007 .58 .3$ Average $0.5 \ldots 1.01 .0 \ldots$ 2.03477 .513522 .54 .818 .616900 .023 .4 Strong 2.0 ... 3.53 .5 $\ldots 4.04 .0 \ldots 5.015572 .518480 .09382 .521 .425 .412 .943435 .0$ 59,7 Very strong $5.0 \ldots 6.06 .0 \ldots 7.0>7.03212 .52282 .5847 .5$ $4.3 \quad 3.11 .26342 .5$ 8.6 Dismemberment exceeding $5.0 \mathrm{~km}$ / $\mathrm{km} 2$ also occurs in the basin of the Mingechaur reservoir, where it occupies a small area of $8.6 \%$ of the total area of the study area. An analysis of the topographic basis shows that the density of ravines is different in the territory: its value in separate contours of the degree of dissection varies from 0.1 to 15.5 pcs / km2. From it can be seen that the data indicate the average density of the ravines.

See results are in good agreement with the data on the degree of dismemberment: with a low degree of dismemberment, on average, 0.44 ravines per $1 \mathrm{~km} 2$ of area, and with a dismemberment of $5.0 \ldots 7.0 \mathrm{~km} \mathrm{/} \mathrm{km2} \mathrm{and} \mathrm{more} \mathrm{-} 7.91$ pcs / $\mathrm{km} 2$. Density of ravines at various degrees of dissected plots № $\mathrm{p} / \mathrm{p}$ the degree of infestation of the area by ravines splitting of the territory, $\mathrm{km} / \mathrm{km} 2$ Density of ravines, units / km2 in Medium Varies 1. Weak 2. Average 3. Strong 4. Very strong $5 \mathrm{~km} / \mathrm{km} 2$ ) the plots are marked mainly in the area of Babaeldag and Bozdag mountains, as well as on the northeastern slopes of the Palantokyan ridge facing directly to the lake.

Of particular interest is the dissection of the territory of individual ravine systems, the orders of their ramification,

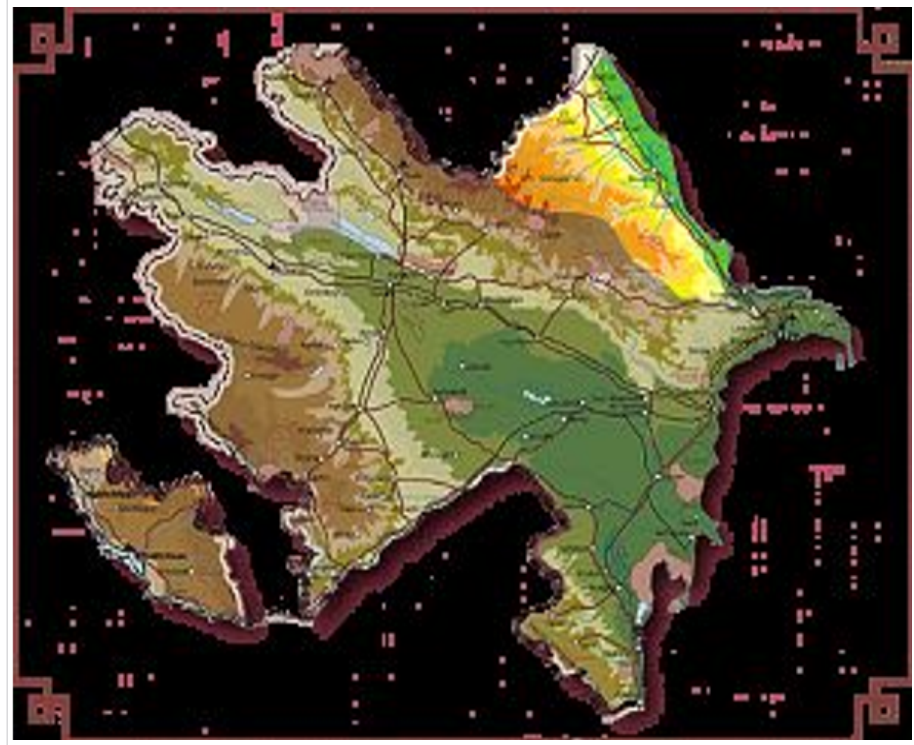

Figure 1 
since the intensity of destruction largely depends on them. An analysis of the topographic basis has established that within the territory of the Mingechaur reservoir basin, the area of which is $720 \mathrm{~km} 2$, there are 750 separate gully systems.

The degree of dismemberment of the territory of these gully systems varies from 0.30 to $16.66 \mathrm{~km} / \mathrm{km} 2$, which is associated with a large difference in the conditions of the formation of ravines in the specified gully systems.

As is known, the intensity of development of individual ravines depends on their catchment area $[7,8,9,14,15]$. But the degree of dismemberment of individual ravine systems depending on the area of their catchment area, as the authors of this study believe, is unknown. In order to clarify this question, on the topographic basis of more than 100 ravine systems, measurements and calculations are overloaded. Data on the catchment area of individual gully systems is given. They show that of the 79 gully systems that have a small catchment area - from 0.02 to $0.47 \mathrm{~km} 2$, only in 4 - the degree of dismemberment.

It is less than $1.0 \mathrm{~km} / \mathrm{km} 2$, and in 36 gully systems - from 5.0 to $7.5 \mathrm{~km} / \mathrm{km} 2$, in 12 - from 7.5 to $10.0 \mathrm{~km} \mathrm{/} \mathrm{km2,} 4$ from 10,0 to 15.0 , and in the 1 st gully system - more than $15 \mathrm{~km} / \mathrm{km} 2$. The Number of gully systems with different catchment area and degree of subdivision Area of catchment of individual gully systems, $\mathrm{km} 2$ Degree of dismemberment of ravine systems Number of ravine systems, 15 pcs. Up to 0.50 .5 to 1.01 .0 to 3,0 from 3.0 to 5.0 from 5.0 to $7.0>7.0$ 4 - - - - 331494536222793119742 - - 12 - 1 - . 4 - . - - . - - 7932462076 Also controversial data were obtained on ravine systems that have a large catchment area. In the ravine systems having a catchment area of 3.0 ... $5.0 \mathrm{~km} 2$, there are 20 of them in the basin, the degree of dismemberment in 9 ravine systems is $1 \ldots 3 \mathrm{~km} / \mathrm{km} 2$, in 9 - $3 \ldots 5 \mathrm{~km} / \mathrm{km} 2$, only in 2 divisions reaches $5 \ldots 7.5 \mathrm{~km} /$ $\mathrm{km} 2$. In the ravine systems with the largest catchment area ranging from 5.0 to $28.8 \mathrm{~km} 2$, the degree of dismemberment of the ravine systems is small, ranging mainly from 1 to $3 \mathrm{~km} /$ $\mathrm{km} 2$, less often from 3 to $5 \mathrm{~km} / \mathrm{km} 2$. As can be seen from the above, the degree of dismemberment of individual gully systems is not dependent on their catchment area, moreover, the greatest dismemberment is observed in the gully systems that have the smallest catchment area, which is associated with the conditions of their location.

On the territory of the basin, ravines relate mainly to the 1 and 2 orders of branching, but there are 3 and 4 orders of branching here. Places of distribution of the order of branching in the tertiary plateau Branching orders The places of the greatest distribution of orders

I The coastal strip of the reservoir, the gentle southern and eastern slopes of Mount Palantokan, the eastern and western parts of the Khojashin ranges, the areas west of the Bozdag range (the vicinity of the Kirov mountain), the right bank and the left bank of the Iori river.
II The lower part of the slopes of Mount Bozdag, the coastal strip of the reservoir, the lower part of the northeastern slopes of the Palantokan ridge.

III Steep slopes in the central part of the Bozdag Range, the upper part of the northeastern slopes of the Palantokan Range.

IV Steep slopes north-west of Mount Babaeldag, steep slopes in the western part of the Khojashin ridge.

When analyzing the topographic baseline, the I and II orders of branching are distinguished mainly to the coastal strip of the reservoir, to the gentle slopes and lower parts of the mountains. The largest orders of branching have spread in the upper part of the steep slopes.

The degree of dismemberment of the territory does not depend on the depth of local bases of erosion. As can be seen from the data of, within the relative heights from $0 \ldots 117$ to ... $417 \mathrm{~m}$, the degree of partitioning of the territory varies in small ranges - from 2.28 to $3.45 \mathrm{~km} / \mathrm{km} 2$. Moreover, with a base depth of up to $417 \mathrm{~m}$, the degree of dismemberment is

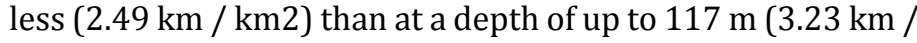
$\mathrm{km} \mathrm{2).} \mathrm{This} \mathrm{is} \mathrm{apparently} \mathrm{due} \mathrm{to} \mathrm{the} \mathrm{fact} \mathrm{that} \mathrm{in} \mathrm{the} \mathrm{places} \mathrm{with}$ the greatest depths of local erosion bases, the lower part of the slopes is shallow, and also because there is a less dissected inclined plain between the mountain part and the reservoir, which reduces the overall degree of dissection.

The areas with the smallest depth of local bases of erosion with their steep, short slopes are directly facing the lake. The degree of dismemberment of the territory depending on the depths of local erosion bases, km / km2 No. n / a Depth of local Area, km2 Length Degree of bases of erosion, m network, $\mathrm{km}$ of dismemberment, km / km2 1. 0 to $1178.7519,42.28$ 2. From 0 to 217217.10718 .33 .293 . From 0 to 317170.94 589.23 .454 . From 0 to 417 and more than 73.95196 .42 , 49 as mentioned above, there are 750 ravine systems in the basin of the Mingechaur reservoir. Of these ravine systems, tens of thousands of tons of soil and soil are carried away by rainwater every year. However, not all ravine systems are connected with the reservoir and not all erosion products enter the reservoir.

Calculations made on a large-scale topographic basis show that of all 750 gully systems in the territory, only 3 of its bed, cut in an inclined plain to a depth corresponding to the degree of fragmentation, reaches the final point - the reservoir, taking out a huge amount of erosion products from the mountains and collapses of unstable rocks.

In a number of such gully systems, even on densely overgrown banks of channels (on an inclined plain), Grebenchuk with a height of up to 8 ... $10 \mathrm{~m}$ and a trunk diameter at the root neck of up to $10 \mathrm{~cm}$, when they find mudflows, they lie down and can not to keep the erosion products from the mountains, and the flow of water with the washed-off material completely reaches the reservoir. 
Ravine systems that do not have a direct connection between them reach the plain and the flow of water with washed material fan-likely dissipates in the upper and middle parts of the inclined plain. Conclusion On the territory of the tertiary plateau, the combination of a number of components of the arid-denudation landscape contributes to intensive erosion and washing away of the soil. Determined that territories with soils not subject to erosion occupy (in $\%$ of the total area) 21.3 , medium and highly washed - 49.3, bedrock outcrops - 15.7. Gully erosion covers from the entire area of the territory $68.3 \%$, of which the area of dissection is $2.0 \ldots 7.0$ pcs / km2 and more. It is established that gully erosion covers the entire area of the study area. At $68.3 \%$ of the area, the ruggedness is $2.0 \ldots 7.0 \mathrm{~km} / \mathrm{km} 2$ and more, and the density of ravines in some places reaches 15.5 pieces / $\mathrm{km} 2$.

Out of 79 gully systems that have a small catchment area - from 0.02 to $0.47 \mathrm{~km} 2$, only in the 4 th degree of dismemberment is less than $1.0 \mathrm{~km} / \mathrm{km} 2$, and in 36 gully systems from 5.0 to $7.5 \mathrm{~km} / \mathrm{km} 2$, in 12 - from 7.5 to 10.0 $\mathrm{km} / \mathrm{km} 2$, in 4 - from 10.0 to 15.0 , and in the 1st gully system - more than $15 \mathrm{~km} / \mathrm{km} 2$. The degree of dismemberment of individual gully systems is not dependent on their catchment area, which is associated with the conditions of their location.

The density of the ravines in some places reaches $15.5 \mathrm{~km} /$ $\mathrm{km} 2$. The average annual growth of ravines is $0.34 \ldots 7.48 \mathrm{~m}$ in length, $0.20 \ldots 2.48 \mathrm{~m}$ in width, and $0.10 \ldots 1.16 \mathrm{~m}$ in depth. The intensity of the development of ravines is influenced by their catchment area. On the territory of the tertiary plateau, ravines mainly belong to the I and II orders of the branching, but there are also branches of the III and IV orders, which are confined mainly to the steep slopes of the upper parts of the gully systems. In order to weaken the erosion processes and reduce the intensity of the ravines of the Mingechaur reservoir, it is necessary to carry out organizational, economic, agrotechnical, ameliorative and hydrotechnical measures.

\section{References}

1. Veretennikova MV The mechanism of ravine erosion and the dynamics of channel forms. Geomorphology. 1998; 2: 66-75.

2. Jarullaev ASH. Features of the development of erosion processes in the winter pastures of the Ajinour massif and measures to combat them: Author. dis. Cand. s.-x. sciences. Baku, 1989.

3. Zaslavsky MN. Erosurology, Moscow: Higher School. 1983; 320.

4. Zorina EF. Gully erosion: patterns and development potential. M. GEOS. $2003 ; 189$.

5. Zorina EF, Nikolskaya II. The ravines are one of the links in a single erosion network. Geomorphology. 2008; 3: 23-29.

6. Kuznetsov MS. Anti-erosion resistance of soils. Moscow: Publishing House of Moscow State University. 1981; 135.

7. Rozhkov AG. Bakhirev GI, Gorin VB. The intensity of the growth of ravines in the central black soil zone. Soil Science. 1993; 4: 84-88.

8. Khalilov SHB. The main geographical problems of interaction of large reservoirs with the environment (on the example of the Republic of Azerbaijan): author. dis. ... dock geogr. Sciences. Baku, 1996.

9. Khisainov NS. Development of gully erosion and forest reclamation techniques to combat it in central Tajikistan: author. dis ... Cand. S. H. sciences. Dushanbe. 2006; 21.

10. Eyubov FD. The experience of studying the dynamics of the ravines of the Agenourian foothills using aerospace images. To the VII delegate congress of the All-Union Society of Soil Scientists: materials of the congress. Baku: Elm. 1985; 46. 